\title{
The Impact of Social Marketing on Public Behavior
}

\author{
Christian Bach and Enas Alnajar
}

\begin{abstract}
Social marketing utilizes the traditional commercial marketing strategies to influence public behaviors effectively so as to bring about greater social/public good. While similar to commercial marketing, social marketing does not attempt to maximize profit or sales, rather the goal of social marketing campaigns is to change a behavior in the society which will benefit the overall public such as persuading people to use only efficient lighting so as to conserve energy or persuading more individuals to use seat belts. To this end, it is crucial for social marketers to ensure that they use effective marketing plans and strategies such as the 4 Ps of the marketing mix in combination with other factors such as policies and partnerships in order to make the social marketing program or campaign a success. To this end, this paper explored how social marketing can have a significant impact on public behavior if social marketing campaigns are deployed keeping in view traditional marketing strategies and plans.
\end{abstract}

Index Terms - Social marketing, public behaviors, success, challenges.

\section{INTRODUCTION}

Social marketing as a distinct discipline aims to promote behaviors which can benefit individuals as well as the overall society $[1,2]$. To this end, it is a proven behavior change discipline which has had a profound impact on influencing public behaviors which can not only improve public health, but can also protect the environment, prevent injuries and contribute towards sustainable development within communities [3]. Hence, social marketing can be applied to different situations and audiences to influence change in behavioral patterns, in other words, social marketing can be applied wherever there is a target audience and a behavior which should be changed/influenced including but not limited to the reduction of drunk driving, convincing people to use public transportation, increase family planning in developing nations, urging people to use insecticide treated nets to prevent the spread of malaria in African nations etc. [4, 5].

At the core of social marketing lies its audience orientation or how it attempts to target what people want and the reasons for their actions/habits. Social marketing takes an audience centered approach instead of an organization centered approach to systematically view a specific issue [6, 7]. Hence, it can be said that the exchange theory forms the core of this approach where new behaviors have to have a higher value as opposed to the current behaviors. The main objective of social marketing therefore is not to merely change attitudes or enhance awareness of a particular problem, but to empower and motivate people to fully adopt the desired behavior as a part of their daily lives $[8,9]$.

Published on November 18, 2016.
Overall, social marketing can be called a structure or framework as opposed to a theory, as it combines a variety of disciplines such as sociology, psychology, communication theory and anthropology and is therefore an interdisciplinary cross-sector approach for influencing public behavior for social good [10]. Nevertheless, it can be said that social marketing is still a developing field with the potential for much success and bringing about positive change by influencing public behaviors significantly [11] However, it has significant challenges such as measuring its effectiveness, which can be often difficult as it can emphasize specific criteria instead of looking at the broader implications of the change. Regardless of such challenges and limitations, social marketing has been used to effectively change behaviors in fields related to public health and safety from substance abuse, nutrition, physical activities etc, both in developing as well as developed nations $[12,13]$.

Typically, social marketing targets often complex and controversial behaviors by providing distant and delayed benefits to target audiences who often fail to recognize that they have a problem. Hence, social marketing can be defined as harnessing the market forces to change behavior for public good on a massive scale [14]. To this end, marketing can help in bringing about a change in behavior both by inspiring organizations and people regarding the potential for being involved in the positive change. As per research, if people are actually motivated to change and then shown the correct path to implement that change while provided adequate support, positive change can be selfsustaining and internalized $[15,16]$. This serves to reinforce the benefits of incorporating social marketing, which can be used to ensure that ideas which can change negative behaviors/practices into good behaviors/practices are actually implemented, resulting in lasting change for the target audience. If done correctly, then social marketing can provide sustainable and internalized change in behavior [1, 17].

Therefore, the purpose of this research paper will be to explore and understand the techniques and impact of social marketing and how it can be used to influence public behavior on a massive scale.

\section{DISCUSSION}

\section{A. Evolution of Marketing to Influence Public Behavior}

Traditionally, the concept of marketing has been associated with notions such as overconsumption, materialism, and exploitation due to its primary use as a tool to pursue private interests [2]. Nevertheless, there lies a distinction between the tools and the purpose the tools are used for - the use of marketing tools can be used by 
organizations to attract more consumers while libraries, public universities etc. can similarly use marketing techniques and principles to attract more readers/applications which can serve to raise the rate of literacy and education $[18,19]$. Hence, all organizations use marketing to boost their products, which are not necessarily associated with generation of profit. To this end, marketing as a tool can be used in the pursuit of social/public good. This broadening in the concept of marketing has therefore made place for the new field of social marketing [20].

According to Laasch \& Conaway (2014), researching the concept of social marketing in the 1950s, mass media channels including television and radio can prove to be an effective means of promoting social ideals. However, the first study focusing on the field of social marketing was conducted by Zaltman and Kotler in 1971 who formally coined the term social marketing and defined the main purpose of social marketing as a way to spread social ideas through marketing research, product planning, pricing, communication and distribution [8]. This definition was further narrowed down in 1989 by Kotler, Lee and Roberto in their book 'Social Marketing: Improving the Quality of Life' and thereby defined the field as the application of commercial marketing techniques and concepts towards achieving social good. This was further improved upon when Andreasen released his definition of social marketing which states that the main objective of social marketing is to impact voluntary behaviors [21]. To this end, social marketing has three main characteristics applying commercial marketing techniques to influence behavior, which primarily benefits the society, families or individual and not the marketing organization in charge of the program [9]. Hence, social marketing as a modern concept can be defined as the application of commercial marketing principles to non-commercial ideals and behaviors [17]. Social marketing also combines the four 'Ps' of marketing product, price, promotion and place towards public communication campaigns [22].

\section{B. Social Marketing and Focus on Behavior as the Bottom Line}

The main purpose or aim of social marketing is to bring about positive behavior change within individuals, families and societies. Hence, the most important aspect of social marketing is to ensure that the selected strategy or tactics have a definite impact on consumers [12, 23]. This customer centric approach leads to the need for research, which is specifically designed to understand target audiences before developing social marketing programs [24]. Furthermore, it is vital for social marketers to include utilize key tactics and strategies as well as monitor behavior during the programs so as to ensure that they are having the desired impact on overall behaviors [25]. Also, within the field of social marketing, success should not be measured by the beliefs changed, lectures provided or messages distributed but rather the behavioral change observed over time relating to the specific behavior which is being targeted [3]. Hence, social marketing uses exposure theories and behavioral persuasion, which targets specific changes in risky behavior [26]. The theory of persuasion for example is based on how people have to engage in elaboration of message, which refers to developing positive thoughts regarding the message being conveyed in order to be persuaded in the long term [27]. Similarly, social marketers base campaigns on how the length and intensity of exposure can impact certain behaviors. Social marketers therefore use theories to identify key determinant of the behavior being targeted so it can be modified on a mass scale [6]. For example, social marketing campaigns based around the reduction of obesity can use behavioral theory to identify the link between behavioral determinants of poor nutrition such as availability of high calorie and low nutrition food and eating habits within the family and overall community along with the depiction of fast food in advertising. These factors can be used in social marketing campaigns to develop complex pathways and conceptual frameworks, which can lead to changes in behavior [28]. Overall, it can be said that the main purpose or bottom line of social marketing is to impact public behaviors which can be measured according to the changes in the behavior of the target audience whereas commercial marketing always has a bottom line of direct benefit which can be easily measured in monetary values [29]. Hence, social marketing campaigns can be called a success where change occurs but there is no direct benefit to the social change organization or the marketer [4].

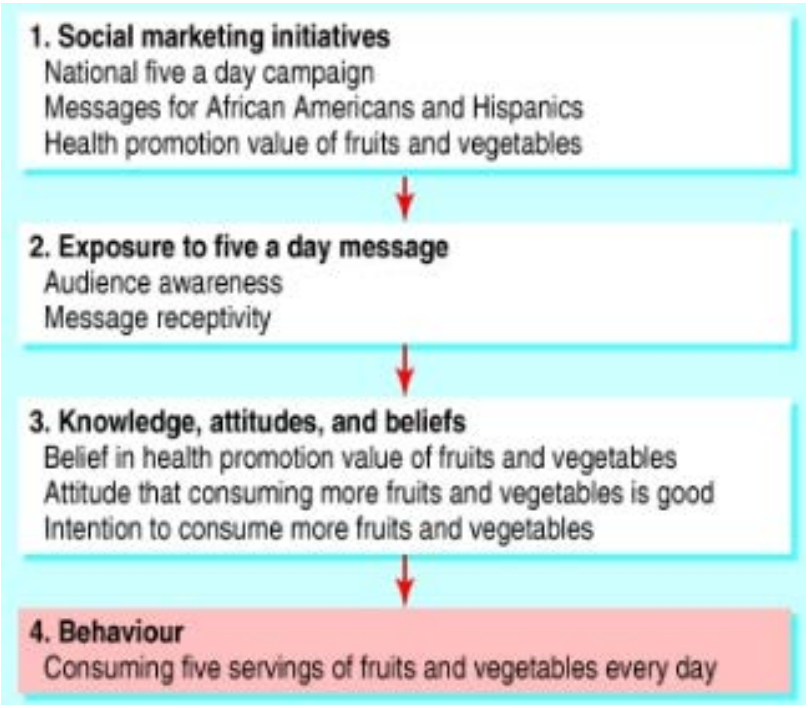

Fig. 1. Example of a Social Marketing Framework for Health Promotion amongst Hispanics and African Americans

\section{Criteria for Social Marketing Programs}

Most studies conducted in the field of social marketing suggest that social marketing programs and campaigns should include a clear focus on behavior change, research phase, audience segmentation for the target group, a focus on exchange theory, application of the marketing mix and consideration of competition [30]. As the purpose of social marketing is to either make its target audience accept or reject a potential behavior or modify/abandon old behaviors, it should be noted that behavior such behavior change has to be voluntary so customer orientation can be applied to analyze what target audiences believe in, know and do [6].

As per the exchange theory, humans have a natural inclination to improve and are need-directed. This supports the foundation of social marketing where exchanges are 
commanded or coerced but have to be voluntary. Hence, social marketers should be able to clearly identify a benefit for the target audience and which they will be interested in receiving in exchange of adopting/dropping behaviors [31]. The product here is the behavior, which is problematic to be exchanged, and many times the benefits might not be immediately clear to the target audience [32]. However, social marketers have a duty to present information and benefits for the target audience regardless of whether the change in behavior is achieved. Hence, exchange between parties is not always the outcome of a social marketing program [28]. To this end, the theory of social exchange can better be applied towards social marketing campaigns as it called for actions which are dependent on rewarding reactions from the target audience [33].

\section{Phases of Social Marketing Programs}

Social marketing is similar to commercial marketing in its consumer driven philosophy where social marketers identify the target audience's wants, needs, perceived benefits and costs as well as current behaviors through research [15]. Once these factors are identified, marketing mix can be applied successfully. Therefore, the process of audience segmentation of the target group is a crucial part of designing social marketing interventions [29].

As the core of both social and commercial marketing is the marketing mix or the 4 Ps of marketing - product, price, place, and promotion. In the context of social marketing, product is the new behavior and the benefits, which can be achieved/received by adopting the behavior. Price is what the individual will have to give in exchange for adopting the new behavior, referring to the potential inconvenience which individuals can face while adopting or dropping the behavior [34]. Place is the 'marketplace' where the exchange can happen - in the context of social marketing, certain environmental factors have to be present which can facilitate the adoption/rejection of behaviors. Lastly, promotion refers to the effort, which is needed to communicate the benefits of the product to the target audience [35].

Furthermore, advertising is an equally crucial part of promotion but can be commonly mistaken for a social marketing program. The problem in social marketing lies with the 'product' being offered behaviors are intangible [17]. Hence, besides the four traditional Ps of marketing, social marketing also incorporates partnerships and policy as equally crucial parts of the marketing mix [36]. For example, when the desired changes are greater than the reach or resources of a social marketing program, it can be useful to engage in partnerships with other organizations, which share similar aims and goals. Similarly, effective policies can also help in enforcing and facilitating long-term behavior change [28, 32].

\section{E. Success of Social Marketing Programs}

Social marketing aims to bring about healthy changes within behaviors of a specific target group, thereby resulting in campaigns which are designed to bring about the greater good for society [34]. Nevertheless, it is often difficult to evaluate the success of social marketing programs as they aim to change widespread behaviors within the public [11].

Hence, social marketers should evaluate programs based on three basic steps - formative evaluation which serves to identify the target population and behavior the program has to address, process evaluation which allows an understanding of how the program or campaign is progressing and performing and lastly, summative evaluation which serves to determine if the program has met the set goals [32, 37]. However, despite a noticeable behavior change after targeted a social marketing program, its success can still not be measured easily due to the influence of external factors - for example, a campaign designed to reduce smoking amongst teens cannot be definitely called a success even if there is noticeable reduction in the number of teen smokers due to factors such as increasing price, availability of certain brands etc. [35].

Hence, the effectiveness of social marketing can best be highlighted from studying mass communication and social marketing campaigns, which can change behaviors and behavioral mediators [7]. For example, the American Legacy Foundation's Truth campaign designed to reduce the prevalence of smoking amongst young people in the US decreased significantly to 18 percent from 25.3 percent, where it is estimated that the program was responsible for around 22 percent of the reduction. Similarly, the percentage of increased seat belt use in the US can be attributed to a variety of factors such as publicity campaigns from Mothers Against Drunk Driving, Click it or ticket program which served to illustrate the importance of primary seat belt laws as well as the easy availability of seat belts [32]. Moreover, various campaigns such as the Swiss Stop AIDS Program which attempt to control and prevent the spread of HIV/AIDS promote the use of condoms with casual partners achieved a success of 50 to 80 percent in condom use [28, 29, 37]. 


\section{F. Challenges of Social Marketing}

There are various examples of unsuccessful social marketing campaigns such as the 'US Got milk?' campaign that highlighted the difficulties of attempting to achieve behavior change within the mass public. Despite being wellfunded and running over five years, this campaign did not achieve the desired increase in the sale of milk due to various external factors such as the increase in price of raw milk and competition from the bottled water industry [38]. To this end, social marketers face various difficulties which are related to external factors as well as challenges from breaking into already crowded marketing environment and industries - for example, the tobacco industry in the US is very well established which means additional challenges for campaigns designed to reduce the use of tobacco $[6,15]$. Similarly, not following the established marketing plan elements such as the 4 Ps of marketing along with policies and partnerships can also lead to failure of the social marketing program [4]. Furthermore, the modern society is filled with media messaging which serves to effectively attract individuals, thereby making it difficult to promote the obvious value of new services and goods [18, 34]. Hence, the promotion of changes in behavior amongst the public is more difficult, especially since the long term effect or price may not be obvious to individuals at first [12] Also, many social marketers do not use effective market research techniques or do not develop the necessary strategy for development of the campaign such as the marketing mix elements, the 4 Ps [27, 33].
III. SURVEY, ANALYSIS AND RESULTS

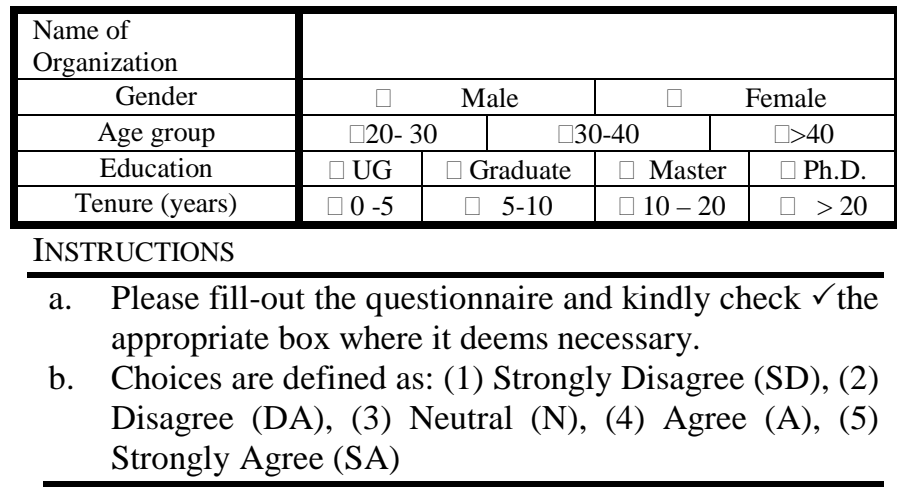

\begin{tabular}{|c|c|c|c|c|c|}
\hline Question Statements & $\begin{array}{l}\text { SA } \\
\text { (1) }\end{array}$ & $\begin{array}{c}\text { A } \\
\text { (2) }\end{array}$ & $\begin{array}{c}\mathrm{N} \\
(3)\end{array}$ & $\begin{array}{c}D \\
(4)\end{array}$ & $\begin{array}{l}\text { SD } \\
\text { (5) }\end{array}$ \\
\hline $\begin{array}{l}\text { The main objective of social } \\
\text { marketing is to impact voluntary } \\
\text { behaviors. }\end{array}$ & & & & & \\
\hline $\begin{array}{l}\text { The main purpose or aim of social } \\
\text { marketing is to bring about positive } \\
\text { behavior change within individuals, } \\
\text { families and societies }\end{array}$ & & & & & \\
\hline $\begin{array}{l}\text { Due to the customer centric approach } \\
\text { of social marketing, there is a need to } \\
\text { understand target audiences before } \\
\text { developing social marketing } \\
\text { campaigns. }\end{array}$ & & & & & \\
\hline $\begin{array}{l}\text { Social marketers should be able to } \\
\text { clearly identify a benefit for the target } \\
\text { audience. }\end{array}$ & & & & & \\
\hline $\begin{array}{l}\text { Social marketing should also } \\
\text { incorporate partnerships and policy } \\
\text { along with } 4 \text { Ps of marketing mix. }\end{array}$ & & & & & \\
\hline $\begin{array}{l}\text { It is difficult to evaluate the success of } \\
\text { social marketing programs as they aim } \\
\text { to change widespread behaviors within } \\
\text { the public }\end{array}$ & & & & & \\
\hline $\begin{array}{l}\text { Challenges faced by social marketers } \\
\text { include difficulties related to not } \\
\text { following the elements of an } \\
\text { established marketing plan. }\end{array}$ & & & & & \\
\hline $\begin{array}{l}\text { Social marketers should avoid the } \\
\text { temptation of discounting the } \\
\text { importance of strategic marketing } \\
\text { planning. }\end{array}$ & & & & & \\
\hline
\end{tabular}

The responses of the survey participants to the inquiry that the main objective of social marketing is to impact the voluntary behaviors are depicted in the preceding bar chart and frequency table. Majority of the participants representing nearly half of the population agreed that social marketing significantly influences the voluntary behaviors of the individuals. On the other hand, out of 50 participants, 12 contradicted with the statement by responding to disagree or strongly disagree scale. The second question intended to attain the opinions of the participants regarding the concept that the chief purpose of social marketing is to stimulate 
positive behavior among the individuals, families and societies. 14 participants strongly agreed with the statements while 17 agreed with it. However, 8 participants acquired a neutral outlook to the proposed notion. The outcomes from the third question represent the perspectives of the participants of the survey when asked whether due to the customer centric approach of social marketing, there is a need to understand target audiences before developing social marketing campaigns. A large number of participants constituting 54 percent of the total populace presented their responses in favor of the statement. On the other hand, 14 members of the survey contradicted with the statement. The forth table replicates the viewpoints of the participants when asked to share their perspective about the conception that social marketing must also emphasize on policy and partnerships along with the 4Ps of marketing mix. A significant division of the members of the survey presented their answer favor of the statement. These participants responded to either agree or strongly agree scale. In contrast 16 percent of the population surveyed believed that social marketing must not incorporate policy and partnerships along with 4Ps of marketing mix. The fifth question was included in the questionnaire with the aim to attain the opinions of the participants regarding the concept that social marketers should be able to clearly identify a benefit for the target audience. 15 participants strongly agreed with the statements while 14 agreed with it. However, 7 participants acquired a neutral outlook to the proposed notion. On the other hand, the participants contradicting with the statement averaged up to 28 percent. In response to the query that it is difficult to evaluate the success of social marketing programs as they aim to change widespread behaviors within the public, 48 percent of the survey participants have agreed. 13 percent presented neutral response. The seventh question along with the bar chart replicates the viewpoints of the participants when asked to share their perspective about the statement that challenges faced by social marketers include difficulties related to not following the elements of an established marketing plan. A significant division of the members of the survey presented their answer favor of the statement. These participants responded to either agree or strongly agree scale. In contrast 20 percent of the population surveyed did not agree with it. The purpose of including the eighth question was to gather the responses of the participants on the idea that social marketers should avoid the temptation of discounting the importance of strategic marketing planning. 58 percent of the total participants agreed with it.

\section{DISCUSSION}

The utilization of quantitative research design based on the survey generated a number of findings of the study. The outcomes of the survey clearly indicated that the fundamental aim of social marketing is to influence the behavior of the individuals and it brings about a positive behavior change within individuals, families as well as society. This finding of the study was in line with the researches carried out by Burchell, Rettie \& Patel, (2013); Tobey, Koenig, Brown \& Manore, (2016). The researchers pointed out that social marketing stimulate positive change in the individuals and society as whole. The findings of the current study also revealed that policy and partnerships must be considered as an integral part of the social marketing along with the 4 Ps of marketing mix. The existing literature also supports this outcome of the research carried out by Laasch \& Conaway, 2014 who indicated that besides the four traditional Ps of marketing, social marketing also incorporates partnerships and policy as equally crucial parts of the marketing mix. Another finding of the study states that it often becomes difficult to evaluate the success of social marketing programs as they aim to change widespread behaviors within the public. This finding was in line with the research performed Frantz, Flynn, Atwood, Mostow, Xu \& Kahl, (2016) who pointed out not following the established marketing plan elements such as the 4 Ps of marketing along with policies and partnerships can also lead to failure of the social marketing program.

\section{CONCLUSIONS}

All in all, it can be said that social marketing is an adaption of commercial marketing techniques and technologies for programs which are designed to influence voluntary behaviors amongst the target audience so as to bring about improvements in their personal welfare as well as effect behavior within the overall society towards the greater social good. Hence, the bottom line or core objective of social marketing is to bring behavioral change in the society - for example to encourage more teens to quit smoking in a specific state. Social marketing is therefore not a science but rather a discipline, which relies on various subjects to create programs, which can influence human behavior on a mass scale. It differs from commercial marketing as it does not target specific product choice behaviors, product promotion behaviors or purchase behaviors and where individuals are asked to switch brands, bur products etc. but it typically targets complex and controversial behaviors present in the society and attempts to bring about an ideal change. Social marketing has been known to be successful in persuading groups and individuals to adopt positive behaviors such as those related to public health or the environment. Such positive behavioral change is associated with the social marketers' abilities to apply proven commercial marketing and planning research/methods along with selected behavior related tools towards encouraging certain behaviors or even discouraging specific behaviors or habits such as smoking. Furthermore, according to the literature explored above, it is clear that social marketing utilizes the benefits of doing social good for the public so as to secure customer engagement and therefore, its primary focus is on providing for positive behavior change. By using a customer centric approach, social marketing also uses various tools of marketing such as the 4 Ps of the marketing mix in conjunction with policies and partnerships to strengthen the marketing strategies and to create a competitive advantage by constantly responding to and instigating change within public behavior. The findings generated from the outcomes of the survey affirm that social marketing has a positive impact on the public behavior. Therefore, it can be deduced that by utilizing social marketing techniques, positive behaviors can be stimulated among individuals and society. Nevertheless, 
despite of evidence, which proves the success of social marketing, the discipline is still under-utilized while societal problems such as the degradation of public health are worsening. To this end, social marketers need to implement

\section{REFERENCES}

[1] Lefebvre, R.C., An integrative model for social marketing. Journal of Social Marketing, 2011. 1(1): p. 54-72.

[2] Luca, N.R. and L.S. Suggs, Theory and model use in social marketing health interventions. Journal of health communication, 2013. 18(1): p. 20-40.

[3] Levinson, J.C., F. Adkins, and C. Forbes, Guerrilla Marketing for Nonprofits. 2010: Entrepreneur Press.

[4] Frantz, C.M., et al., Changing Energy Behavior Through Community Based Social Marketing, in The Contribution of Social Sciences to Sustainable Development at Universities. 2016, Springer. p. 259272.

[5] Olson, S.J., Social Marketing and Social Change Strategies and Tools for Health, Well-Being, and the Environment. Health promotion practice, 2014. 15(3): p. 309-312.

[6] Alaimo, K., et al., Project FIT: a school, community and social marketing intervention improves healthy eating among low-income elementary school children. Journal of community health, 2015 40(4): p. 815-826.

[7] Muralidharan, S. and K. Sheehan, "Tax" and "Fee" Message Frames as Inhibitors of Plastic Bag Usage Among Shoppers A Social Marketing Application of the Theory of Planned Behavior. Social Marketing Quarterly, 2016: p. 1524500416631522.

[8] Opel, D.J., et al., Social marketing as a strategy to increase immunization rates. Archives of pediatrics \& adolescent medicine, 2009. 163(5): p. 432-437.

[9] Smith, W.A., Social marketing: an overview of approach and effects. Injury prevention, 2006. 12(suppl 1): p. i38-i43.

[10] Tyson, B., Social Influence Strategies for Environmental Behavior Change. 2013: iUniverse; Wakefield, M.A., B. Loken, and R.C. Hornik, Use of mass media campaigns to change health behaviour. The Lancet, 2010. 376(9748): p. 1261-1271.

[11] Vlasov, M. and C. Mark-Herbert. Enabling behaviour change-Social Practice Theory perspective on social marketing strategy. in 4th Nordic Conference on Consumer Research. 2016.

[12] Tobey, L.N., et al., Reaching Low-Income Mothers to Improve Family Fruit and Vegetable Intake: Food Hero Social Marketing Campaign-Research Steps, Development and Testing. Nutrients, 2016. 8(9): p. 562.

[13] Wymer, W., Rethinking the boundaries of social marketing: Activism or advertising? Journal of Business Research, 2010. 63(2): p. 99103.

[14] Peattie, K. and S. Peattie, Social marketing: A pathway to consumption reduction? Journal of Business Research, 2009. 62(2): p. 260-268

[15] Andreasen, A.R., Rethinking the relationship between social/nonprofit marketing and commercial marketing. Journal of Public Policy \& Marketing, 2012. 31(1): p. 36-41.

[16] Rhindress, M., Understanding how to motivate communities to support and ride public transportation. Vol. 122. 2008: Transportation Research Board.

[17] Andreasen, A.R., WhatIs Social Marketing? The Handbook of Persuasion and Social Marketing [3 volumes], 2014: p. 13.

[18] Lee, N.R. and P. Kotler, Social marketing: Influencing behaviors for good. 2011: Sage.

[19] Maibach, E.W., C. Roser-Renouf, and A. Leiserowitz Communication and marketing as climate change-intervention assets: A public health perspective. American journal of preventive medicine, 2008. 35(5): p. 488-500.

[20] Nathanson, J., From Marketing to Meaning: Toward a Reconceptualization of Social Marketing. 2008: ProQuest.

[21] Andreasen, A.R., Social marketing in the 21st century. 2006: Sage Publications.

[22] Thackeray, R. and B.L. Neiger, A multidirectional communication model: Implications for social marketing practice. Health promotion practice, 2009. 10(2): p. 171-175.

[23] Burchell, K., R. Rettie, and K. Patel, Marketing social norms: social marketing and the 'social norm approach'. Journal of Consumer Behaviour, 2013. 12(1): p. 1-9.

[24] Bakan, J., Social marketing: thoughts from an empathetic outsider. Journal of Marketing Management, 2016. 32(11-12): p. 1183-1189; campaigns for various societal issues that can help or influence the society to move away from a culture of harm. This will ensure sustainable progress and eradication of many harmful behaviors.

Rundle-Thiele, S., Looking back and moving forwards: An agenda for social marketing research. Recherche et Applications en Marketing (English Edition), 2015. 30(3): p. 128-133.

[25] McKenzie-Mohr, D., Fostering sustainable behavior: An introduction to community-based social marketing. 2013: New society publishers.

[26] Brennan, L., et al., Social marketing and behaviour change: Models, theory and applications. 2014: Edward Elgar Publishing.

[27] Chen, Y.-c., A Study of citizen purchasing behaviors toward lowcarbon food based on the viewpoint of Social Marketing. 2015.

[28] Friedman, A.L., et al., Health communication and social marketing campaigns for sexually transmitted disease prevention and control: What is the evidence of their effectiveness? Sexually transmitted diseases, 2016. 43(2S): p. S83-S101.

[29] Stewart, D.W., The Handbook of Persuasion and Social Marketing [3 volumes]. 2014: ABC-CLIO.

[30] Abroms, L.C. and E.W. Maibach, The effectiveness of mass communication to change public behavior. Annu. Rev. Public Health, 2008. 29: p. 219-234; Takahashi, B., Social Marketing for the Environment: A Comparative Analysis of Theory and Practice. 2007: ProQuest.

[31] Dann, S.M., Social change marketing in the age of direct benefit marketing-where to from here? 2005; Evans, W.D., Social Marketing Research for Global Public Health: Methods and Technologies. 2016: Oxford University Press.

[32] French, J. and R. Gordon, Strategic social marketing. 2015: Sage.

[33] Evans, W.D., How social marketing works in health care. Bmj, 2006. 332(7551): p. 1207-1210.

[34] Hastings, G., K. Angus, and C. Bryant, The Sage handbook of social marketing. 2011: Sage.

[35] Kotler, P., N. Roberto, and N. Lee, Social Marketing: Improving the Quality of Life.

[36] Laasch, O. and R.N. Conaway, Principles of responsible management: Glocal sustainability, responsibility, and ethics. 2014 Nelson Education.

[37] Kubacki, K., et al., Minimizing alcohol harm: A systematic social marketing review (2000-2014). Journal of Business Research, 2015. 68(10): p. 2214-2222.

[38] Dann, S., Redefining social marketing with contemporary commercial marketing definitions. Journal of Business Research, 2010. 63(2): p. 147-153. 